\section{Public Health Response to a Human Immunodeficiency Virus Outbreak Associated with Unsafe Injection Practices - Roka Commune, Cambodia, 2016}

Ugonna C. Ijeoma, MD ${ }^{1,2}$; Sin Sansam, MD³; Sok Srun, MD³ ${ }^{3}$ Hoy Vannara, $\mathrm{MD}^{3}$; Sou Sanith, $\mathrm{MD}^{3}$; Tek Sopheap, $\mathrm{MD}^{3}$; Robert D. Newman, $\mathrm{MD}^{2}$; Renuka Gadde, $\mathrm{MBA}^{4}$; Selenic Dejana, $\mathrm{MD}^{2}$; Ahmed Saadani Hassani, MD ${ }^{2}$; Vanthy Ly, $\mathrm{MD}^{2}$; Bakary Drammeh, $\mathrm{DrPH}^{2}$; Anindya De, $\mathrm{PhD}^{2}$; Johnita Byrd, $\mathrm{MS}^{2}$; Naomi Bock, $\mathrm{MD}^{2}$

Cambodians receive 0.8-5.9 therapeutic injections per person per year, one of the highest reported rates worldwide $(1,2)$. Appropriate medical injections and infusions can be health sustaining or lifesaving; however, improper administration can have detrimental health consequences, including infectious disease transmission (3). In 2000, it was estimated that worldwide, unsafe injection and waste disposal practices account for 260,000 new human immunodeficiency virus (HIV) infections annually (3).

A case-control study conducted as part of an investigation of an outbreak of 242 new cases of HIV infection among residents of Roka Commune, Battambang Province, Cambodia, from December 2014 through February 2015, (4) identified unsafe medical injection practices by an unlicensed health care practitioner as the likely source of the outbreak, highlighting the potential for unsafe therapeutic injection practices to contribute to HIV transmission in Cambodia. After this outbreak, the government of Cambodia implemented new regulations to prohibit unlicensed medical practices (5). Although the outbreak was associated with the unregulated health sector, it prompted an assessment of injection safety practices among licensed health care workers in Cambodia, given the high public demand for medical injections. To identify potential gaps in safe injection practices, the Cambodia Ministry of Health $(\mathrm{MOH})$ partnered with CDC and the medical technology company Becton Dickinson (Franklin Lakes, New Jersey) to conduct a rapid assessment of injection practices at public health facilities.

From September 26-29, 2016, a team of medical officers from CDC and a clinical team from Becton Dickinson with expertise in infection control assisted the Cambodia $\mathrm{MOH}$ in implementation of the rapid assessment. A cross-sectional study* was conducted among the 15 main government health care facilities in Battambang and Pursat provinces, which are among the provinces with the highest medical injection rates (1) and are in close proximity to the site of the 2014-2015 HIV

\footnotetext{
*This study was conducted with the approval of the Cambodia National Ethics Committee for Health Research.
}

outbreak. A World Health Organization (WHO) standardized injection practices assessment tool ( $($ ) was used to interview licensed health care workers, including physicians, nurses, and laboratory technicians, and observe all injections administered. Injection technique was evaluated using a standardized checklist. The interview questions ascertained knowledge, attitudes, and practices regarding injection use and safety. Frequencies were calculated, and, given the limited sample size, exact 95\% confidence intervals were estimated using statistical software.

A total of 115 injection events were observed, and 39 health care workers were interviewed (Table); 99\% of injections were administered with needles and syringes taken from unopened, sterile packs. However, patient identification was not confirmed before injection in $54 \%$ of events, hand hygiene procedures did not precede injection in $79 \%$ of events, and a new cotton swab was used in only $36 \%$ of events. Observation of safety practices demonstrated that $63 \%$ of health care workers recapped needles after use; $51 \%$ were recapped with two hands. Less than half (48\%) of sharps containers were appropriately placed within arm's length of health care worker; however, most needles $(83 \%)$ were still placed in a sharps container immediately after use. All 39 interviewed health care workers knew that HIV could be transmitted through unsafe injection practices, but fewer were aware of the potential for transmission of hepatitis B virus (79\%) and hepatitis C virus (62\%) through this route. Finally, $28 \%$ of health care workers reported ever experiencing a needle stick injury, and $49 \%$ reported ever receiving formal injection safety training.

Although this study found little reuse of injection equipment and high knowledge of the risks of unsafe injection practices related to HIV transmission, none of the observed injections fully adhered to WHO standards of practice, thus potentially compromising both patient and health care worker safety. To address these gaps, an intensive training curriculum on safe injection practices for health care workers is being developed by Becton Dickinson with technical support from CDC. After review and approval by the Cambodia $\mathrm{MOH}$, expert master trainers will administer this training in the same health care facilities where the baseline assessment was conducted. The impact of the training on the improvement of injection and phlebotomy practices will be measured with a follow-up assessment in the same facilities where the baseline assessment was conducted. Health assessment findings are also contributing to the revision of current policies, information education and communication resources, and the development of job aids on safe injection practices. 
TABLE. Assessment of safe injection knowledge, attitudes, and practices among health care workers - Battambang and Pursat provinces, Cambodia, 2016

\begin{tabular}{|c|c|c|}
\hline Assessment component (No. assessed) & No. & $\%(95 \% \mathrm{Cl})$ \\
\hline \multicolumn{3}{|l|}{ Observation of injection administration (115) } \\
\hline \multicolumn{3}{|l|}{ Procedures affecting patient safety } \\
\hline Sterile needle/syringe used for injection (112) & 111 & $99(95-100)$ \\
\hline $\begin{array}{l}\text { Patient identification not confirmed before injection } \\
\text { (113) }\end{array}$ & 61 & $54(44-63)$ \\
\hline $\begin{array}{l}\text { Hand hygiene not performed before injection } \\
\text { administration (115) }\end{array}$ & 91 & $79(71-86)$ \\
\hline $\begin{array}{l}\text { Injection site cleaned with a newly moistened cotton } \\
\text { swab (110) }\end{array}$ & 40 & $36(27-46)$ \\
\hline \multicolumn{3}{|l|}{ Procedures affecting health care worker safety } \\
\hline Needle recapped after use (104) & 65 & $63(52-72)$ \\
\hline Recapped with two hands (65) & 33 & $51(38-63)$ \\
\hline $\begin{array}{l}\text { Sharps container placed within arm's reach of health } \\
\text { care worker (106) }\end{array}$ & 51 & $48(38-58)$ \\
\hline $\begin{array}{l}\text { Needle disposed of in sharps container immediately } \\
\text { after use (109) }\end{array}$ & 91 & $83(75-90)$ \\
\hline \multicolumn{3}{|l|}{ Health care worker interviews (39) } \\
\hline \multicolumn{3}{|l|}{ Aware of disease transmission via unsafe injections } \\
\hline Human immunodeficiency virus & 39 & $100(91-100)$ \\
\hline Hepatitis B & 31 & $79(64-91)$ \\
\hline Hepatitis C & 24 & $62(45-77)$ \\
\hline Ever experienced needle-stick injury & 11 & $28(15-45)$ \\
\hline Received formal training on injection safety practices & 19 & $49(32-65)$ \\
\hline
\end{tabular}

Abbreviation: $\mathrm{Cl}$ = confidence interval.

\section{Acknowledgments}

Cambodia Provincial Health Departments, Battambang and Pursat; Becton Dickinson team, Franklin Lakes, New Jersey and Sandy, Utah; Trista Bingham, Michelle Chevalier, Gaston Djomand, Fatima Mili, Larisa Ozeryansky, Becton Dickinson Global Fellows.

\section{Conflict of Interest}

No conflicts of interest were reported.

${ }^{1}$ Epidemic Intelligence Service CDC; ${ }^{2} \mathrm{HIV}$ Prevention Branch, Division of Global Health and TB, CDC; ${ }^{3}$ Ministry of Health, Phnom Penh, Cambodia; ${ }^{4}$ Becton, Dickinson and Company, Franklin Lakes, New Jersey.

Corresponding author: Ugonna Ijeoma, wbv4@cdc.gov, 404-639-5386.

\section{References}

1. National Institute of Statistics; Directorate General for Health; ICF Macro. Cambodia demographic and health survey 2010. Phnom Penh, Cambodia: National Institute of Statistics, Directorate General for Health; Calverton, MD: ICF Macro; 2011. https://dhsprogram.com/pubs/pdf/FR249/ FR249.pdf

2. National Institute of Statistics; Directorate General for Health; ICF International. Cambodia demographic and health survey 2014. Phnom Penh, Cambodia: National Institute of Statistics, Directorate General for Health; Rockville, MD: ICF International; 2015. https://dhsprogram. com/pubs/pdf/FR312/FR312.pdf

3. Hauri AM, Armstrong GL, Hutin YJ. The global burden of disease attributable to contaminated injections given in health care settings. Int J STD AIDS 2004;15:7-16. https://doi.org/10.1258/095646204322637182

4. Vun MC, Galang RR, Fujita M, et al.; Roka Cluster Investigation Team. Cluster of HIV infections attributed to unsafe injection practicesCambodia, December 1, 2014-February 28, 2015. MMWR Morb Mortal Wkly Rep 2016;65:142-5. https://doi.org/10.15585/mmwr.mm6506a2

5. Saphonn V, Fujita M, Samreth S, et al. Cluster of HIV infections associated with unsafe injection practices in a rural village in Cambodia. J Acquir Immune Defic Syndr 2017;75:e82-6. https://doi.org/10.1097/ QAI.0000000000001295

6. World Health Organization. Revised injection safety assessment tool (tool c-revised). Geneva, Switzerland: World Health Organization; 2008. http:// www.who.int/infection-prevention/tools/injections/ToolC-revised.pdf 